\title{
Quantifying the characteristics of particulate matters captured by urban plants using an automatic approach
}

\author{
Jingli Yan ${ }^{1,2}$, Lin $\operatorname{Lin}^{1,2}$, Weiqi Zhou, ${ }^{1, *}$, Lijian $\mathrm{Han}^{1}$, Keming $\mathrm{Ma}^{1}$ \\ 1. State Key Laboratory of Urban and Regional Ecology, Research Center for Eco-Environmental Sciences, Chinese Academy of Sciences, Beijing 100085, \\ China. E-mail: jlyan24@163.com \\ 2. University of Chinese Academy of Sciences, Beijing 100049, China
}

\section{A R T I C L E I N F O}

Article history:

Received 3 August 2015

Revised 26 November 2015

Accepted 27 November 2015

Available online 7 January 2016

Keywords:

Particulate matter retention

Urban vegetation

Object-based classification

Size and shape characteristics

Source identification

\begin{abstract}
A B S T R A C T
It is widely accepted that urban plant leaves can capture airborne particles. Previous studies on the particle capture capacity of plant leaves have mostly focused on particle mass and/or size distribution. Fewer studies, however, have examined the particle density, and the size and shape characteristics of particles, which may have important implications for evaluating the particle capture efficiency of plants, and identifying the particle sources. In addition, the role of different vegetation types is as yet unclear. Here, we chose three species of different vegetation types, and firstly applied an object-based classification approach to automatically identify the particles from scanning electron microscope (SEM) micrographs. We then quantified the particle capture efficiency, and the major sources of particles were identified. We found (1) Rosa xanthina Lindl (shrub species) had greater retention efficiency than Broussonetia papyrifera (broadleaf species) and Pinus bungeana Zucc. (coniferous species), in terms of particle number and particle area cover. (2) $97.9 \%$ of the identified particles had diameter $\leq 10 \mu \mathrm{m}$, and $67.1 \%$ of them had diameter $\leq 2.5 \mu \mathrm{m}$. $89.8 \%$ of the particles had smooth boundaries, with $23.4 \%$ of them being nearly spherical. (3) $32.4 \%-74.1 \%$ of the particles were generated from bare soil and construction activities, and $15.5 \%-23.0 \%$ were mainly from vehicle exhaust and cooking fumes.
\end{abstract}

(C) 2015 The Research Center for Eco-Environmental Sciences, Chinese Academy of Sciences. Published by Elsevier B.V.

\section{Introduction}

Airborne particulate matter has been a major air pollutant for decades, particularly in China's urban areas (Han et al., 2015a). Exposure to high concentrations of fine particulate matter, $\mathrm{PM}_{2.5}$, could pose serious threats to human health (Sierra-Vargas and Teran 2012), such as increasing respiratory symptoms, reduction of lung function, and cardiac arrhythmias (Kuttler et al., 2006). Many studies indicated that urban plants can efficiently reduce airborne particles by capturing them on plant leaf surfaces or in leaf wax (Nowak et al., 2006; Pugh et al., 2012). Therefore, particle retention by urban vegetation has been considered as an effective method of ameliorating and preventing airborne particle pollution (Langner et al., 2011).

Different species have distinct PM retention properties because of their physiological, chemical, and morphological features. The surface roughness, hairs, morphology, and the wax of leaves all can affect the adsorption of PM (Beckett et al., 1998). For individual trees, however, leaf area index and air flow are generally considered to be more important to particle retention (Vos et al., 2013). Previous studies on particles captured by plants have mostly focused on particle mass and size distribution (Nowak et al., 2014; Tallis et al., 2011; Terzaghi et al., 2013; Weber et al., 2014) to evaluate the PM

\footnotetext{
* Corresponding author.E-mail: wzhou@rcees.ac.cn (Weiqi Zhou).
} 
capture capacities and monetary value of species. Few studies, however, have examined the particle density per unit (Ottele et al., 2010; Song et al., 2015). Ottele et al., (2010) found that vegetation near the road can capture more particles than that in the woodland, and suggested that the number of particles on a plant leaf was more appropriate in representing the capture capacity than the weight of particles. Song et al. (2015) found that the particles less than $2.5 \mu \mathrm{m}$ accounted for $96 \%$ of the total number of particles on the leaf, and the average number of particles for six coniferous species was $19.5 \times 10^{6} / \mathrm{cm}^{-2}$.

Even less-studied is the morphology (e.g., the size and shape characteristics) of PM captured by plant leaves. The morphological characteristics of the particles, however, have important implications. Firstly, the morphology of particles can affect deposition and transport properties (Stearns et al., 2001) by changing the drag force of individual particles. Secondly, particles can scatter or absorb both incoming solar radiation and thermal radiation emitted from the earth's surface to directly change the radiation balance (Bellouin et al., 2005; Gustafson et al., 2011). Furthermore, the morphologies of airborne particles differ with respect to particle size range, location of sampling, and collection method (Barone and Zhu 2008), and can aid in source identification by revealing the differences in particles formed by different processes or sources (McDonald and Biswas 2004). For example, particles larger than $1 \mu \mathrm{m}$ are mainly from natural sources, while particles below $1 \mu \mathrm{m}$ mostly from anthropogenic sources (Makkonen et al., 2010). Particles with irregular shape are mainly from natural sources, spherical and irregular aggregates are generally from the steel-making process, and particles from car exhausts appear as soot aggregates (Akram et al., 2014).

In this study, we quantified the number, size, and shape characteristics of particles captured by plants using an objectbased classification approach based on scanning electron microscope (SEM) micrographs. We aimed: (1) to quantify and compare the particle retention efficiency of three tree species of different vegetation types in terms of quantitative and area indices; (2) to analyze the characteristics and distribution of particle size and shape based on representative features; and (3) to explore the major sources of ambient particles in terms of the size and shape characteristics of the particles.

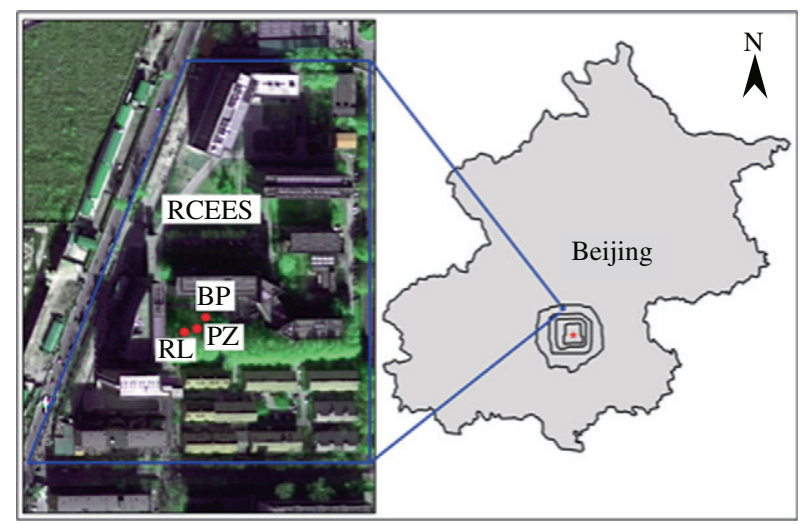

Fig. 1 - The sampling location for three test species, located on the campus of the Research Center for Eco-Environmental Sciences, Chinese Academy of Sciences, between the 4th and 5 th ring road of Beijing, China.

\section{Data collection and processing}

Beijing has been listed as one of the most serious particulate matter polluted cities in the world because of its dense population and rapid urbanization process (Han et al., 2015b). We selected three common tree species of different vegetation types (broad-leaf species Broussonetia papyrifera, BP; coniferous species Pinus bungeana Zucc., PZ; and shrub species Rosa xanthina Lindl, RL) in the campus of the Research Center for Eco-Environmental Sciences, Chinese Academy of Sciences, located in the northeast of Beijing (Fig. 1).

We randomly selected one mature and healthy leaf at the height of $2 \mathrm{~m}$ from each species, and then put them into hermetic bags carefully to avoid further contamination. One sample with the size of $1 \mathrm{~cm}^{2}$ between leaf edge and midrib was cut on a clean and covered operation desk. Then the sample was mounted on an aluminum stub, over double-sided sticky tape, and coated with a thin conductive film of gold in an ion sputter coater (Ram et al., 2012). Coated specimens were examined and photographed under a SEM (Hitachi S-3000N) at an accelerating voltage of 10-15 KV. Finally, micrographs with different magnifications (200x, $500 \times, 1000 \times, 2000 \times)$ were taken on three different spots for each sample (Fig. 2). Considering the resolution and field of view size, SEM micrographs with magnifications of $1000 \times$ were chosen for subsequent analysis after visual inspection. Therefore, three SEM micrographs for each species, and nine total micrographs were analyzed in this study.

\section{Methods}

An automatic particle identification method was designed and adopted in this work. We first applied an object-based image classification approach to automatically identify leaf particles using the SEM micrographs. We then calculated the amount, size, and shape characteristics of the particles on each of the micrographs to quantify the accumulation of leaf particles among the three species. Furthermore, we analyzed the distributions and characteristics of the size and shape of retained particles, from which we explored the possible sources of particles captured on the leaves.

\subsection{Object-based classification}

Here, we applied an object-based classification method on the SEM micrographs to automatically extract the particles captured on the leaves (Yan et al., 2016). In addition to the number of particles captured on leaves that can be counted by the most commonly used visual inspection method (Barone and Zhu 2008; Ram et al., 2012; Slezakova et al., 2009), this approach can obtain a great deal of information on the morphological characteristics of particles. The approach also has higher efficiency and is more objective than the visual inspection method (Yan et al., 2016). Below, we briefly describe the approach. More details can be found in Yan et al. (2016).

Under this approach, image objects were first generated using a multi-resolution segmentation algorithm that is embedded in eCognition Developer ${ }^{\mathrm{TM}}$ software. The 

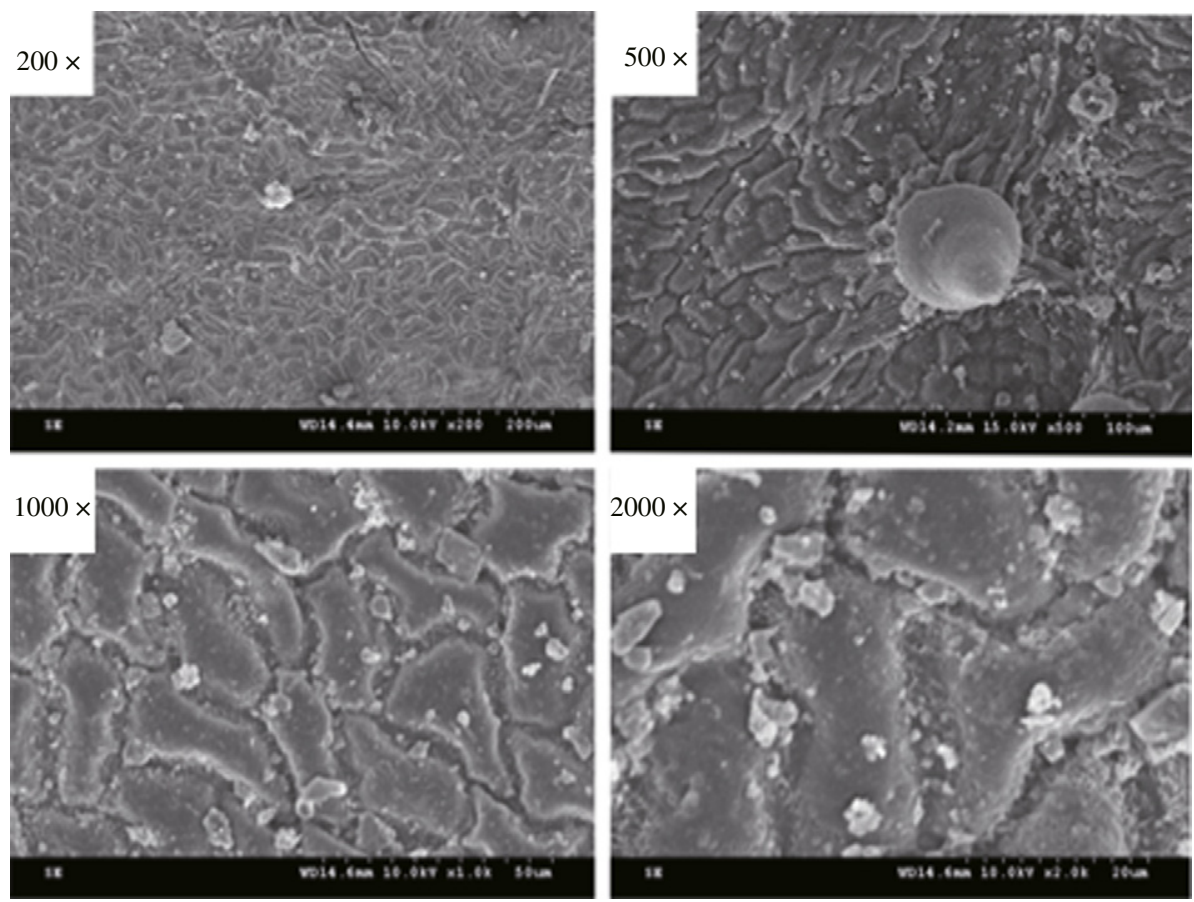

Fig. 2 - The scanning electron microscope micrographs with different magnifications of species Rosa xanthina Lindl (RL).

algorithm initializes each pixel in the image as a separate segment, which is consecutively merged based on level of similarity. The maximum heterogeneity allowed within an image object was defined by a parameter called scale (Benz et al., 2004). The users can also specify two other parameters, shape and compactness, to define the relative weight of reflectance and shape in segmentation. A higher value of scale parameter results in larger objects, and more weight is typically given to color than shape (Zhou and Troy 2008; Pu and Landry 2012). Compactness determines the degree of compactness or smoothness of the objects, which is commonly set to 0.5. In this study, we used Estimation of Scale Parameter (ESP) (Drăguț et al., 2010) to determine the three key parameters (scale, shape, and compactness) for segmentation, considering its efficiency and objectiveness. The results from ESP showed that there were three candidate values for the optimal segmentation scale $-24,54$ and 76 (Fig. 3). We chose the scale parameter of 24 because the boundaries of the small objects $(\leq 2.5 \mu \mathrm{m})$ could be clearly defined at this scale (Fig. 4). Color and compactness were set as common used 0.8 and 0.5 , respectively.

Once the image objects were generated, we applied Classification and Regression Trees (Praagman, 1985; Loh, 2014) to aid in particle classifications. Features were first selected to construct a classification decision tree (De'ath and Fabricius 2000; Laliberte et al., 2012). The resultant decision tree suggested that density and shape index were the two most efficient features, which were then used to develop the ruleset to identify particles from SEM micrographs. When particles were identified, we assessed the accuracy for each species and the overall accuracy for the entire set of nine micrographs. The accuracies are calculated as the number of classified particles divided by a reference, which was counted by two experts together under visual inspection.

\subsection{Particle accumulation of urban plants}

Following the classifications, we assessed and compared the leaf particle accumulations for three plant species at both species level and leaf level. Here, we introduced a new indicator, percentage of leaf area covered by particles (PLA), to quantify the particle capture efficiency, in addition to the commonly used particle number per unit. The PLA is defined as the percentage of area covered by all particles on a SEM micrograph, which can provide additional information on the accumulation of particle retention. The area of particles was calculated in ArcMap based on classification results, and the area of a SEM micrograph was calculated according to the image scale. The particle number identified on a leaf per square centimeter (PNC) was calculated by dividing the number of particles classified by the object-based approach by the area of the SEM micrograph.

\subsection{Characterization of particle size and shape}

In addition to the number and area percent cover of particles, we also summarized the size and shape of the particles retained on the leaves. Distribution diagrams and boxplots were used to summarize the characteristics of size and shape of particles. Previous studies (Barone and Zhu 2008; FreerSmith et al., 1997; McDonald and Biswas 2004) divided aerosol particles into several classes, which were spheres, irregular shaped particles, agglomerates, and fibrous. Therefore, we developed four indicators, diameter, area, border index, and compactness (Table 1), to quantify the size and shape characteristics, and then divided the particles into classes according to the four indicators. Among four indicators, diameter and area are indicators of the actual size of particles, and we used border 


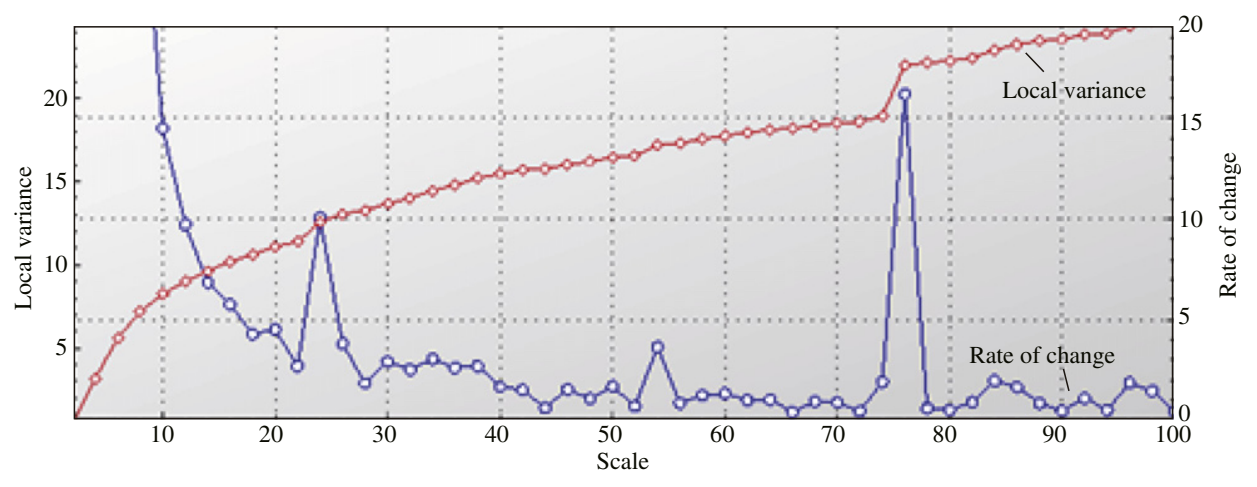

Fig. 3 - The resultant optimal segmentation scales $(24,54,76)$ for species Rosa xanthina Lindl from Estimation of Scale Parameter.

index and compactness to describe the boundary characteristics and overall shape of particles, respectively. These indices were calculated and exported as an Excel table from eCognition Developer ${ }^{\mathrm{TM}}$ based on the classification results.

As for diameter, we classified all particles into four categories using $1,2.5$ and $10 \mu \mathrm{m}$ as the break points. We included $1 \mu \mathrm{m}$ as a break point because Makkonen et al. (2010) suggested that particles larger than $1 \mu \mathrm{m}$ and smaller than $1 \mu \mathrm{m}$ were from different sources. The break points for area were determined based on those for diameter. For the two shape indicators, we equally divided the range into four classes.

\subsection{Identifying potential sources of particles}

A few researchers have investigated the relationship between size and/or shape characteristics and the sources of ambient particles, and they found the characteristics of size and shape of particles were related to their sources and the location of sampling (Akram et al., 2014; Barone and Zhu 2008; Li et al., 2012). We divided the particles captured by leaves into three main classes, which were spheres, irregular particles, and agglomerates, in terms of shape characteristics. First, we classified spheres using compactness $\geq 0.84$ based on visual inspection. Then we identified agglomerate objects from the unclassified objects with area $\geq 25 \mu \mathrm{m}^{2}$ and border index $\geq 1.4$, because the agglomerates were usually bigger in size and their boundaries were more complex than irregular particles. We calculated the proportion of particles for different size and shape classes (Tables 4 and 5). Finally, we explored the possible sources of the three particle categories captured by plants.

\section{Results}

\subsection{Particle retention efficiency}

The object-based approach provided an efficient and accurate method to identify particles adsorbed on plant leaves. The overall accuracy of classification for the three species was $91.21 \%$, with accuracy of $92.17 \%$ for species of BP, $90.43 \%$ for PZ, and $90.95 \%$ for RL (Table 2). Panels in Table 2 clearly show that the surface structure of the leaves varied greatly by species, as well as the number, size and shape of the particles.

The average percentage of leaf area covered by particles (APLA) and the average particle number identified on leaves per square centimeter (APNC) were obviously different among the different tree species. The APLA ranged from 5.44\% for PZ to $13.65 \%$ for RL, and APNC from $0.66 \times 10^{6}$ to $1.95 \times 10^{6}$ (Table $3)$. The retention capacity of RL was significantly greater than that of BP in terms of particle numbers $(p<0.05)$, and significantly greater than BP $(p<0.05)$ and PZ $(p<0.01)$ in terms of percentage of area covered by particles (Fig. 5).

For each species, the APLA and APNC also varied greatly among the three locations (Table 3). For example, the maximum (11.09\%) PLA, the percentage of leaf area covered by particles, of broadleaf species BP was nearly three times of the minimum
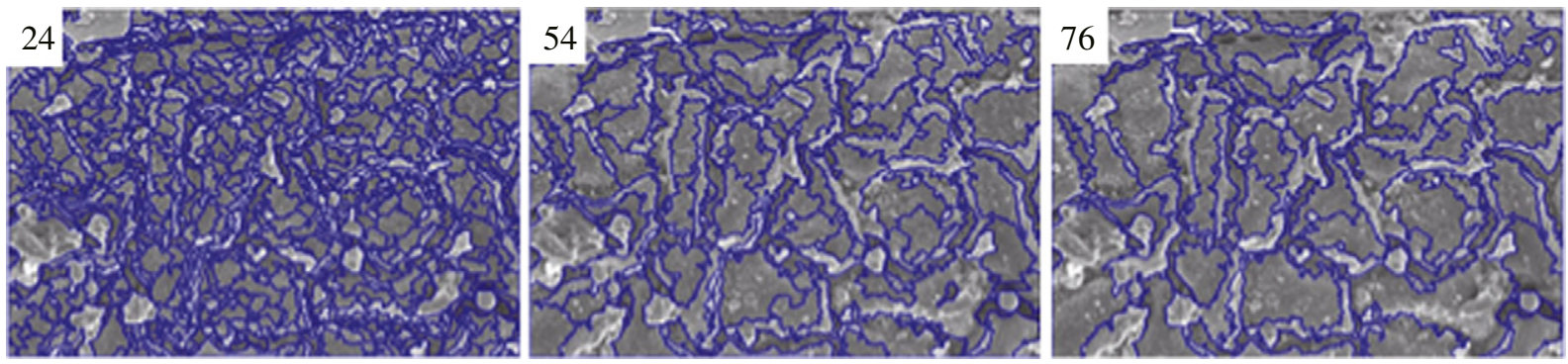

Fig. 4 - The segmentation results using three candidate scales generated from Estimation of Scale Parameter. The blue lines are image object boundaries, and scale 24 can clearly depict the boundaries of small particles. 


\begin{tabular}{|c|c|c|}
\hline Index & Description & Expression \\
\hline Diameter & $\begin{array}{l}\text { The diameter of a circle that with the } \\
\text { same perimeter as a particle object, } \\
\mu \mathrm{m} \text {. }\end{array}$ & $\frac{\text { Perimeter }}{\pi}$ \\
\hline Area & $\begin{array}{l}\text { The area covered by a particle object, } \\
\mu \mathrm{m}^{2} .\end{array}$ & $\frac{\text { Number of pixels }}{25}$ \\
\hline Border index & $\begin{array}{l}\text { The ratio between the border length } \\
\text { and the smallest enclosing rectangle, } \\
\text { describe how jagged an image object } \\
\text { is, } 1-\infty \text {, where } 1 \text { means not jagged. }\end{array}$ & $\frac{\text { Border length }}{2 \text { (length+width) }}$ \\
\hline Compactness & $\begin{array}{l}\text { The ratio of the area of a polygon to } \\
\text { the area of a circle with the same } \\
\text { perimeter, } 0-1 \text {, where } 1 \text { indicates a } \\
\text { circle. }\end{array}$ & $\frac{4 \times \pi \times \text { area }^{2}}{\text { perimeter }^{2}}$ \\
\hline
\end{tabular}

(4.81\%). In addition, the variations in PLA and PNC (the particle number identified on leaves per square centimeter) within the same species differed greatly among different species, where BP had the largest, and RL the least.

\subsection{Distribution of particle size and shape characteristics}

The boxplot provides a convenient manner to graphically depict groups of numerical data through their quartiles. The boxplots show that the medians of size and shape characteristics were similar among the three species, but shrub species RL had more extreme values and greater quartile range (Fig. 6a). In addition, the value of compactness varied more greatly for all species.

The diameters of particles captured by the leaves were all $\leq 23.2 \mu \mathrm{m}$ (Fig. 6b). For all three species, particles were dominated by those with diameter $\leq 10 \mu \mathrm{m}$. $96.3 \%$ of the particles retained by $\mathrm{PZ}$, and $99.1 \%$ by $\mathrm{BP}$ were less than $10 \mu \mathrm{m}$, and more than half of particles had diameters $\leq 2.5 \mu \mathrm{m}$. The leaves of RL adsorbed most particles with diameter $\leq 2.5 \mu \mathrm{m}(68.9 \%)$, and BP had the least (66.3\%). A significant gap existed among species for the number of captured particles with diameter

Table 2 - Examples of classification results and accuracies. The yellow patches are particles identified by the object-based classification method.

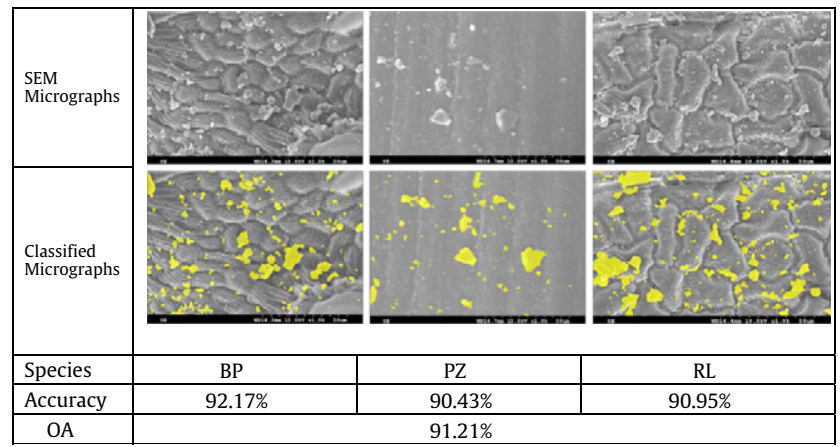

BP: broad-leaf species Broussonetia papyrifera; PZ: coniferous species Pinus bungeana Zucc.; and RL: shrub species Rosa xanthina Lindl. OA: overall accuracy.
Table 3-The particle accumulation on leaves for three species.

\begin{tabular}{crccc}
$\begin{array}{c}\text { SEM } \\
\text { micrograph }\end{array}$ & PLA (\%) & APLA (\%) & PNC cm ${ }^{-2}$ & APNC cm ${ }^{-2}$ \\
\hline BP 1 & 6.89 & 7.60 & $1.39 \times 10^{6}$ & $1.57 \times 10^{6}$ \\
BP 2 & 4.81 & & $0.87 \times 10^{6}$ & \\
BP 3 & 11.09 & & $1.95 \times 10^{6}$ & \\
PZ 1 & 5.47 & 5.44 & $0.64 \times 10^{6}$ & $0.66 \times 10^{6}$ \\
PZ 2 & 4.41 & & $0.55 \times 10^{6}$ & \\
PZ 3 & 6.46 & & $0.78 \times 10^{6}$ & \\
RL 1 & 14.52 & 13.65 & $2.06 \times 10^{6}$ & $1.95 \times 10^{6}$ \\
RL 2 & 14.78 & & $2.28 \times 10^{6}$ & \\
RL 3 & 11.66 & & $1.52 \times 10^{6}$ & \\
\hline
\end{tabular}

PLA: the percentage of leaf area covered by particles, PNC: the particle number identified on leaves per square centimeter. APLA: the average percentage of leaf area covered by particles; APNC: the average particle number identified on leaves per square centimeter.

$\leq 1 \mu \mathrm{m}$, and the percentage of PZ (7.5\%) was less than half that of BP (15.9\%) and RL (17.9\%). 3.7\% of particles captured by leaves of PZ were particles with diameter $\geq 10 \mu \mathrm{m}$, and followed by RL with $2.1 \%$ and BP with $0.9 \%$. The proportion $(7.9 \%)$ of particles larger than $25 \mu \mathrm{m}^{2}$ captured by PZ was greater than that of RL (5.7\%) and BP (2.6\%).

$\mathrm{BP}$ and PZ had similar shape characteristics in terms of border index and compactness, but RL was the exception. Most particles (93.8\% for BP, $89.3 \%$ for PZ, and $86.4 \%$ for RL) had smooth boundaries with border index $\leq 1.4$, and few particle boundaries of RL were extremely jagged. Furthermore, $23.4 \%$ of particles had compactness $\geq 0.84$, which means that the particles were nearly spherical, and $6.6 \%$ of particles of RL showed irregular shape properties with compactness $\leq 0.37$.

\subsection{Potential sources of the particles}

Our results showed $15.5 \%$ of particles with diameter $\leq 1 \mu \mathrm{m}$ (Table 4), which may have originated from anthropogenic sources, such as vehicle exhaust and kitchen fumes (Makkonen et al., 2010). 32.4\% of the particles had diameter $\geq 2.5 \mu \mathrm{m}$, which mainly derived from natural or geological sources. The particles with size between $1 \mu \mathrm{m}$ and $2.5 \mu \mathrm{m}$ were probably from mixed sources (Makkonen et al., 2010). As for plant species, PZ captured the lowest particles with diameter $\leq 1 \mu \mathrm{m}$, and most particles with diameter between 1 and $2.5 \mu \mathrm{m}$.

About $23 \%$ of the particles had spherical shape (Fig. 7; Table 5), and were likely from fuel combustion (Akram et al., 2014). $2.9 \%$ of the particles were agglomerates, including soot aggregates, and mineral or dust aggregates (Fig. 7). The soot aggregates were typically from vehicle exhaust, and mineral or soil aggregates were from natural sources. The majority of the particles $(74.1 \%)$ had irregular shape (Table 5), which were mostly from natural sources. For different species, no great differences existed in terms of particle sources, except that BP had a lower proportion (1.3\%) of agglomerates than that of the other two species (4.2\% for PZ, and 3.7\% for RL). 

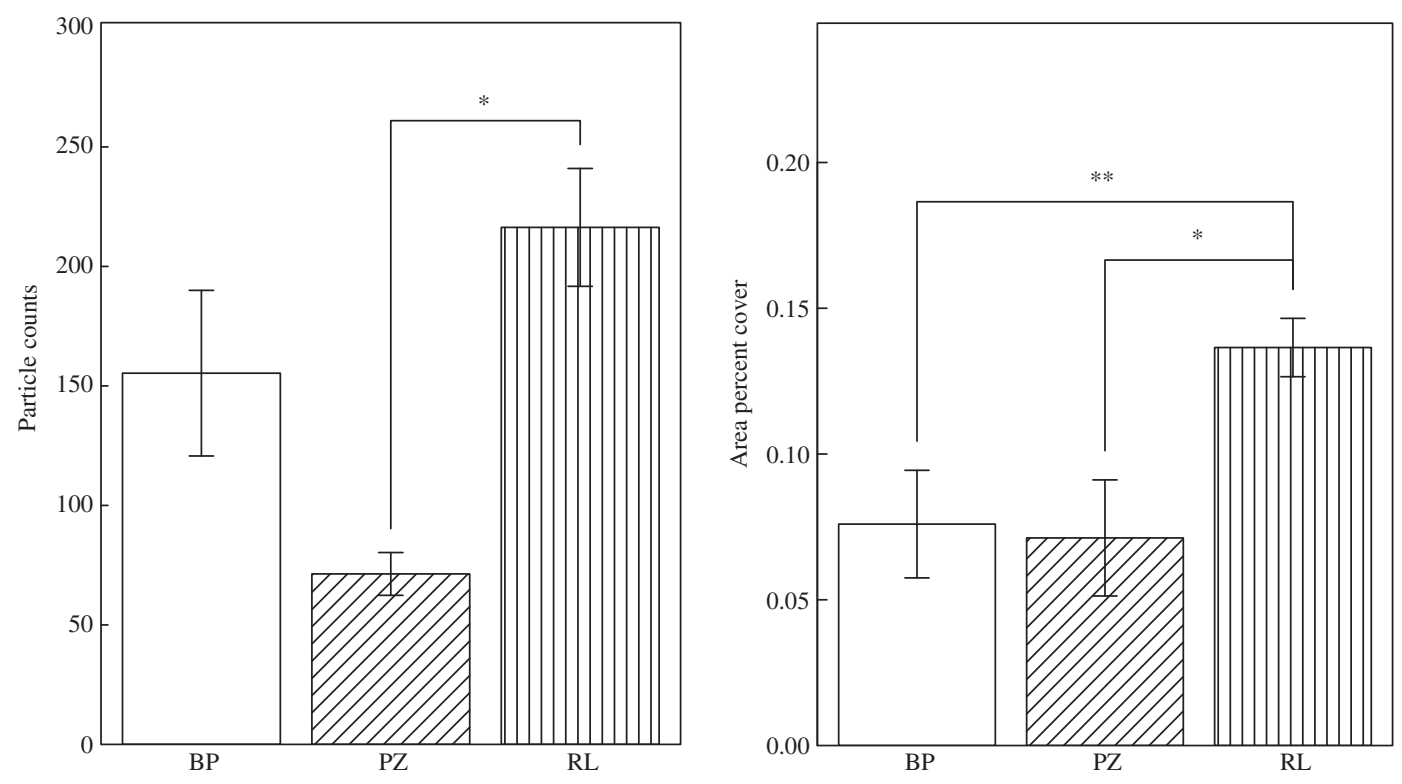

Fig. 5 - Results of analysis of variance (ANOVA) on particle accumulation for different species. "** indicates difference is significant at the 0.05 level, and “**” indicates difference is significant at the 0.01 level.

\section{Discussion}

\subsection{Variations in particle retention of plant species}

We found significant differences in particle accumulation on leaves in terms of number of particles and percentage of leaf area covered by particles, at both species level and leaf level (Table 3). At the species level, the great difference among the three species indicated that different species or vegetation types have distinct capacities for particle retention. These differences may be highly related to vegetation types of species (Beckett et al., 2000a; Popek et al., 2013), leaf structure (Mitchell et al., 2010; Wang et al., 2006), deposition processes (Freer-Smith et al., 2005; Sternberg et al., 2010), location of sample trees, and even meteorological conditions (Beckett et al., 2000b). Among these factors, vegetation types of species and leaf structure are the dominant ones, since the leaves were collected from the same location in our study. Broadleaf species BP and shrub species RL have rough leaf surfaces or cuticular hairs, which can slow down the movement and facilitate the immobilization of particles. In contrast, $\mathrm{PZ}$ is a typical coniferous species with smooth blades and thick cuticle. In addition, the particles that deposited on the leaves of BP had a tendency to re-suspend or fall off compared with the other two species when air flow changed. We demonstrated that the leaves of the shrub species were much more efficient at particle retention per unit area than broadleaf and coniferous species. However, tree species, especially coniferous species, have significant advantages in particle retention because of their tremendous leaf area index (Beckett et al., 2000b). Therefore, more species of different types with diverse leaf structure under various circumstances need to be studied in future research.

At the leaf level, few studies have investigated the differences in particle retention efficiencies among different locations on the same leaf. Our results showed that different locations on the same leaf also could have different retention efficiencies, which may be due to the combined effects of random deposition processes and leaf characteristics. The shrub species RL had relatively small variations in particle accumulation among the locations, in contrast to the two tree species (Table 3). This difference may be related to the low height of RL, the small size of its leaves, and the density of its leaves, leading to low permeability. Therefore, our results suggested that it may be inappropriate to treat different leaves on same tree, even different locations within one leaf, as the same when considering their exact accumulation in particle adsorption. In addition, future research on the mechanisms of differences in efficiency of particle retention related to leaf location and direction are warranted.

\subsection{Distribution and characteristics of particle size and shape}

More extreme values and greater quartile ranges according to boxplot (Fig. 6a) indicated that the values of shrub species RL were more scattered for all four indices. This also suggested that RL is more adaptive with different kinds of particles compared with the other two species, which was proved by the percentage distribution of particles in Fig. 6b. We speculated that the complex wide and deep creases on the leaf surface of RL (Table 2) are helpful to capture larger and irregular particles.

Furthermore, RL captured the most particles with diameter $\leq 2.5 \mu \mathrm{m}$ (68.9\%), which probably can access to the respiratory tract and cause related diseases. Therefore, shrub species RL are more efficient at protecting people from airborne particle pollution. Coniferous species PZ captured the most particles with diameter $\geq 10 \mu \mathrm{m}$ and the least very fine particles with diameter $\leq 1 \mu \mathrm{m}$, which is the reason why PZ has the lowest average particle number per centimeter, but a relatively higher average percentage by area (Table 3). 
A
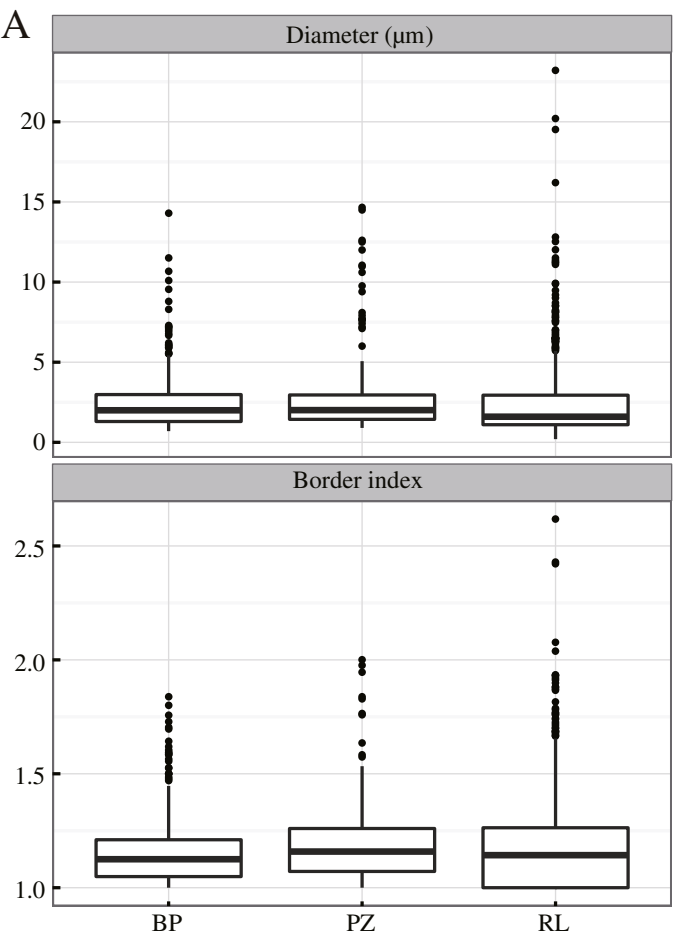

Species

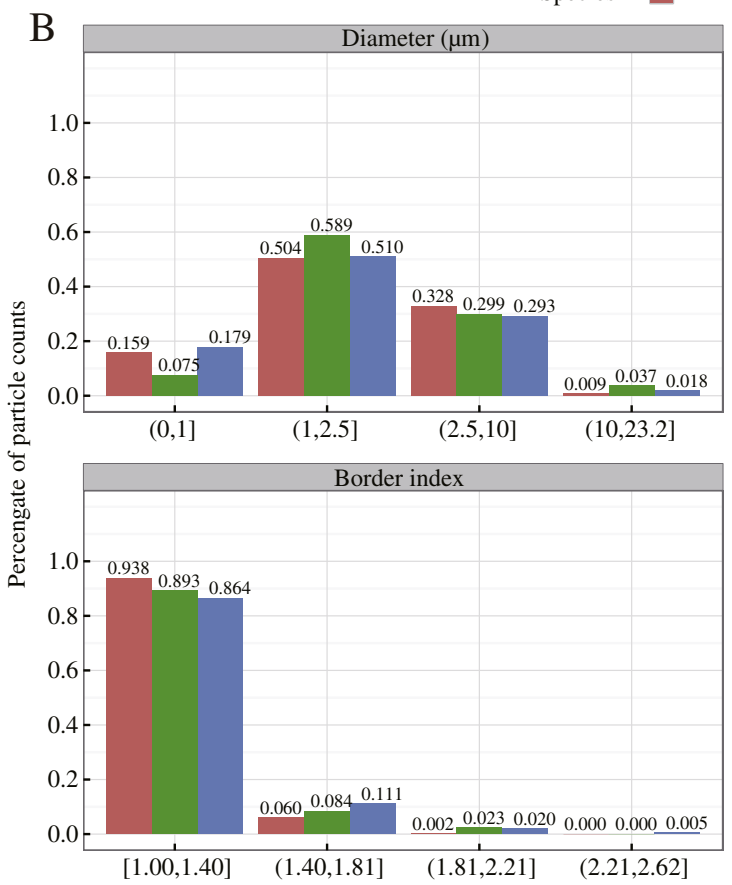

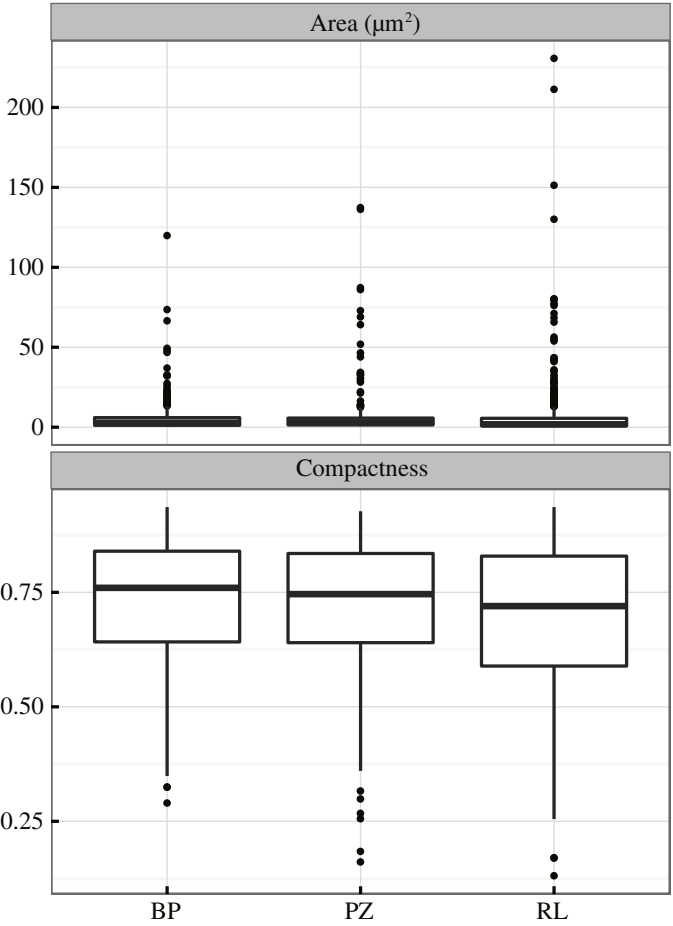

PZ RL

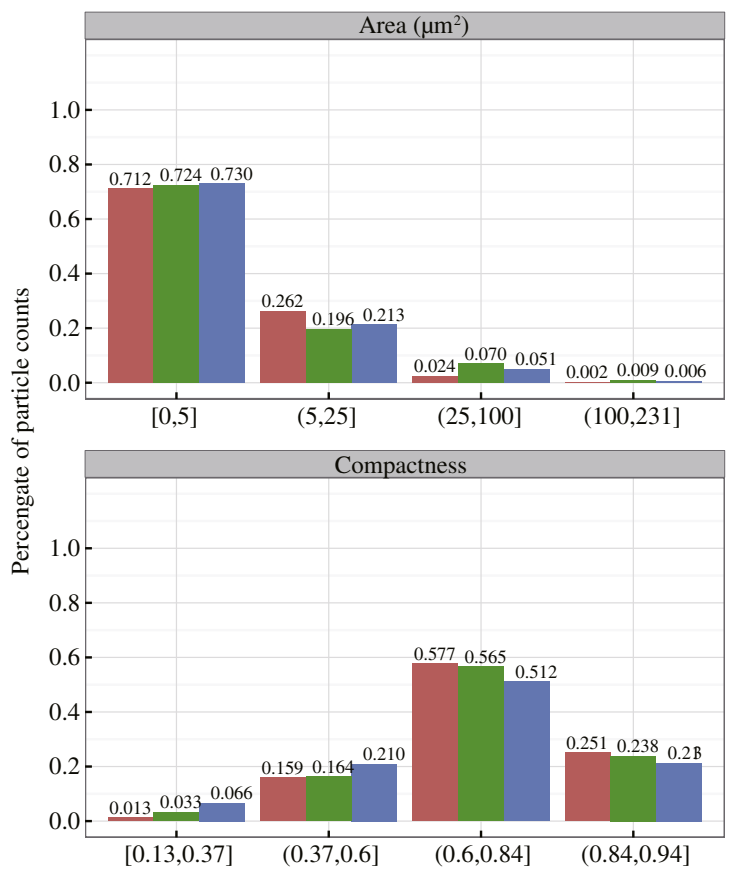

Fig. 6 - The descriptive statistics of the four indicators for the three species; (a) the distribution of particle values of four indicators for three species; (b) the proportion distribution of particles of four indicators for three species.

Table 4 - The particle number and proportion of three particle size classes for three species, $\mu \mathrm{m}$.

\begin{tabular}{ccccc} 
Diameter & $0-1 \mu \mathrm{m}$ & $1-2.5 \mu \mathrm{m}$ & $2.5-23.2 \mu \mathrm{m}$ & Total \\
\hline BP & $74 /(15.9 \%)$ & $235 /(50.4 \%)$ & $157 /(33.7 \%)$ & \\
PZ & $16 /(7.5 \%)$ & $126 /(58.9 \%)$ & $72 /(33.6 \%)$ & $21 \%$ \\
RL & $116 /(17.9 \%)$ & $332 /(51.0 \%)$ & $202 /(31.1 \%)$ & 650 \\
Total & $206 /(15.5) \%$ & $693 /(52.1 \%)$ & $431 /(32.4 \%)$ & 1330 \\
\hline
\end{tabular}



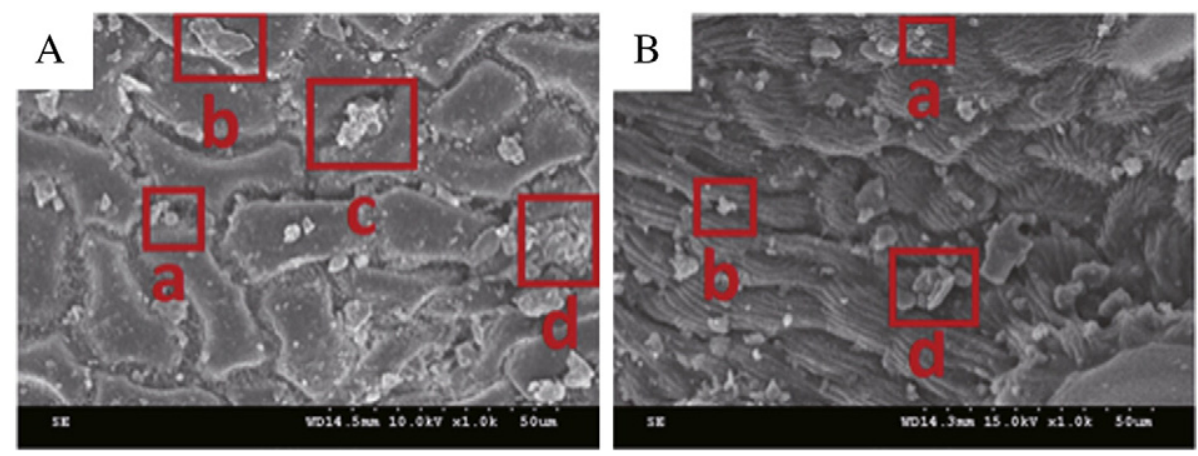

Fig. 7 - Examples of different morphological types of captured particles. Panel A: a scanning electron microscope (SEM) micrograph of RL, Panel B: a SEM micrograph of BP. a: spheres; b: irregular particles; c: soot aggregates: d: mineral or dust aggregates.

\section{Conclusions}

We applied an object-based classification approach to quantify and compare the number, size, and shape characteristics of particles captured by three species of different vegetation types. We found: (1) the particle retention efficiency of shrub species RL was greater than that of broadleaf species BP in terms of particle numbers, and significantly greater than broadleaf species BP and coniferous species PZ in terms of percentage of leaf area covered by particles; (2) shrub species RL was more efficient at capturing fine particles, $\mathrm{PM}_{2.5}$, which pose more threat to human health, and coniferous species $\mathrm{PZ}$ tended to adsorb bigger particles with diameter greater than $10 \mu \mathrm{m}$; (3) the majority of the particles (from 95.7\% for PZ to 99.1\% for BP) had diameter $\leq 10 \mu \mathrm{m}$, and $54.8 \%$ was $\leq 2.5 \mu \mathrm{m}$; (4) most particles, from $86.4 \%$ of RL to $93.8 \%$ of BP, had smooth edges with border index $\leq 1.4$, and $23.4 \%$ of the particles had approximately spherical shape (compactness $\geq 0.84$ ).

Additionally, we exemplified the use of the morphological characteristics to identify the potential sources of particles. According to the morphological characteristics, $32.4 \%-74.1 \%$ of particles might be from natural sources, mostly soil dusts and construction dusts, and $15.5 \%-23.0 \%$ of particles were from fuel combustion. However, it should be noted that to better link the morphological characteristics of particles to their sources, studies on more species under various circumstances are desirable.

\section{Acknowledgment}

This study was supported by the "One-Hundred Talents" program of the Chinese Academy of Sciences (No. N234), the National Natural Science Foundation of China(Nos. 41430638

Table 5-The particle number and proportion of three particle shape classes for three species.

\begin{tabular}{lrrrr} 
Class & \multicolumn{1}{c}{ Spheres } & Irregular particles & Agglomerates & Total \\
\hline BP & $117 /(25.1 \%)$ & $343 /(73.6 \%)$ & $6 /(1.3 \%)$ & 466 \\
PZ & $50 /(23.4 \%)$ & $155 /(72.4 \%)$ & $9 /(4.2 \%)$ & 214 \\
RL & $138 /(21.2 \%)$ & $488 /(75.1 \%)$ & $24 /(3.7 \%)$ & 650 \\
Total & $305 /(23.0 \%)$ & $986 /(74.1 \%)$ & $39 /(2.9 \%)$ & 1330 \\
\hline
\end{tabular}

and 41301199), and the project "Major Special Project-The China High-Resolution Earth Observation System". We thank Pengfei Zhao for his visual inspection of particles on SEM micrographs.

\section{R E F E R E N C E S}

Akram, W., Madhuku, M., Ahmad, I., Xiaolin, L., Zhang, G., Yan, L., 2014. Morphology, microstructure and chemical composition of single inhalable particles in Shanghai. China Environ. Monit. Assess. 186 (12), 8587-8598.

Barone, T.L., Zhu, Y.F., 2008. The morphology of ultrafine particles on and near major freeways. Atmos. Environ. 42 (28), 6749-6758.

Beckett, K.P., Freer-Smith, P.H., Taylor, G., 1998. Urban woodlands: their role in reducing the effects of particulate pollution. Environ. Pollut. 99 (3), 347-360.

Beckett, K.P., Freer-Smith, P.H., Taylor, G., 2000a. Particulate pollution capture by urban trees: effect of species and windspeed. Glob. Chang. Biol. 6 (8), 995-1003.

Beckett, K.P., Freer Smith, P., Taylor, G., 2000b. Effective tree species for local air quality management. J. Arboric. 26 (1), 12-19.

Bellouin, N., Boucher, O., Haywood, J., Reddy, M.S., 2005. Global estimate of aerosol direct radiative forcing from satellite measurements. Nature 438 (7071), 1138-1141.

Benz, U.C., Hofmann, P., Willhauck, G., Lingenfelder, I., Heynen, M., 2004. Multi-resolution, object-oriented fuzzy analysis of remote sensing data for GIS-ready information. ISPRS J. Photogramm. 58 (3-4), 239-258.

De'ath, G., Fabricius, K.E., 2000. Classification and regression trees: a powerful yet simple technique for ecological data analysis. Ecology 81 (11), 3178-3192.

Drăguț, L., Tiede, D., Levick, S.R., 2010. ESP: a tool to estimate scale parameter for multiresolution image segmentation of remotely sensed data. Int. J. Geogr. Inf. Sci. 24 (6), 859-871.

Freer-Smith, P., Holloway, S., Goodman, A., 1997. The uptake of particulates by an urban woodland: site description and particulate composition. Environ. Pollut. 95 (1), 27-35.

Freer-Smith, P.H., Beckett, K.P., Taylor, G., 2005. Deposition velocities to Sorbus aria, Acer campestre, Populus deltoides $\times$ trichocarpa 'Beaupre', Pinus nigra and $\times$ Cupressocyparis leylandii for coarse, fine and ultra-fine particles in the urban environment. Environ. Pollut. 133 (1), 157-167.

Gustafson, W.I., Qian, Y., Fast, J.D., 2011. Downscaling aerosols and the impact of neglected subgrid processes on direct 
aerosol radiative forcing for a representative global climate model grid spacing. J. Geophys. Res. 116 (7), 28.

Han, L., Zhou, W., Li, W., 2015a. Increasing impact of urban fine particles (PM2.5) on areas surrounding Chinese cities. Sci. Rep. 5 (7), 12467

Han, L.J., Zhou, W.Q., Li, W.F., Meshesha, D.T., Li, L., Zheng, M.Q., 2015b. Meteorological and urban landscape factors on severe air pollution in Beijing. J. Air Waste Manage. Assoc. 65 (7), 782-787.

Kuttler, K.L., Shillor, M., Fernandez, J.R., 2006. Existence and regularity for dynamic viscoelastic adhesive contact with damage. Appl. Math. Optim. 53 (1), 31-66.

Laliberte, A.S., Browning, D.M., Rango, A., 2012. A comparison of three feature selection methods for object-based classification of sub-decimeter resolution UltraCam-L imagery. Int. J. Appl. Earth. Obs. 15 (4), 70-78.

Langner, M., Kull, M., Endlicher, W.R., 2011. Determination of $\mathrm{PM}_{10}$ deposition based on antimony flux to selected urban surfaces. Environ. Pollut. 159 (8-9), 2028-2034.

Li, X.R., Wang, L.L., Wang, Y.S., Wen, T.X., Yang, Y.J., Zhao, Y.N., Wang, Y.F., 2012. Chemical composition and size distribution of airborne particulate matters in Beijing during the 2008 Olympics. Atmos. Environ. 50 (4), 278-286.

Loh, W.Y., 2014. Fifty Years of Classification and Regression Trees. International Statistical Review 82 (3), 329-348.

Makkonen, U., Hellen, H., Anttila, P., Ferm, M., 2010. Size distribution and chemical composition of airborne particles in south-eastern Finland during different seasons and wildfire episodes in 2006. Sci. Total Environ. 408 (3), 644-651.

McDonald, R., Biswas, P., 2004. A methodology to establish the morphology of ambient aerosols. J. Air Waste Manage. Assoc. 54 (9), 1069-1078.

Mitchell, R., Maher, B.A., Kinnersley, R., 2010. Rates of particulate pollution deposition onto leaf surfaces: temporal and inter-species magnetic analyses. Environ. Pollut. 158 (5), 1472-1478.

Nowak, D.J., Crane, D.E., Stevens, J.C., 2006. Air pollution removal by urban trees and shrubs in the United States. Urban For. Urban Gree. 4 (3), 115-123.

Nowak, D.J., Hirabayashi, S., Bodine, A., Greenfield, E., 2014. Tree and forest effects on air quality and human health in the United States. Environ. Pollut. 193 (10), 119-129.

Ottele, M., van Bohemen, H.D., Fraaij, A.L.A., 2010. Quantifying the deposition of particulate matter on climber vegetation on living walls. Ecol. Eng. 36 (2), 154-162.

Popek, R., Gawronska, H., Wrochna, M., Gawronski, S.W., Saebo, A., 2013. Particulate matter on foliage of 13 woody species: deposition on surfaces and phytostabilisation in waxes - a 3-year study. Int. J. Phytorem. 15 (3), 245-256.

Praagman, J., 1985. Classification and Regression Trees - Breiman, L, Friedman, Jh, Olshen, Ra, Stone. Cj. European Journal of Operational Research 19 (1), 144.
Pu, R., Landry, S., 2012. A comparative analysis of high spatial resolution IKONOS and WorldView-2 imagery for mapping urban tree species. Remote Sens. Environ. 124 (9), 516-533.

Pugh, T.A.M., MacKenzie, A.R., Whyatt, J.D., Hewitt, C.N., 2012. Effectiveness of green infrastructure for improvement of air quality in urban street canyons. Environ. Sci. Technol. 46 (14), 7692-7699.

Ram, S.S., Majumdar, S., Chaudhuri, P., Chanda, S., Santra, S.C., Maiti, P.K., Sudarshan, M., Chakraborty, A., 2012. SEMEDS: an important tool for air pollution bio-monitoring. Micron 43 (2-3), 490-493.

Sierra-Vargas, M.P., Teran, L.M., 2012. Air pollution: impact and prevention. Respirology 17 (7), 1031-1038.

Slezakova, K., Pires, J.C.M., Pereira, M.C., Martins, F.G., AlvimFerraz, M.C., 2009. Influence of traffic emissions on the composition of atmospheric particles of different sizes-Part 2: SEM-EDS characterization. J. Atmos. Chem. 60 (3), 221-236.

Song, Y., Maher, B.A., Li, F., Wang, X., Sun, X., Zhang, H., 2015. Particulate matter deposited on leaf of five evergreen species in Beijing, China: source identification and size distribution. Atmos. Environ. 105 (3), 53-60.

Stearns, R.C., Paulauskis, J.D., Godleski, J.J., 2001. Endocytosis of ultrafine particles by A549 cells. Am. J. Respir. Cell Mol. Biol. 24 (2), 108-115.

Sternberg, T., Viles, H., Cathersides, A., Edwards, M., 2010. Dust particulate absorption by ivy (Hedera helix L) on historic walls in urban environments. Sci. Total Environ. 409 (1), 162-168.

Tallis, M., Taylor, G., Sinnett, D., Freer-Smith, P., 2011. Estimating the removal of atmospheric particulate pollution by the urban tree canopy of London, under current and future environments. Landsc. Urban Plan. 103 (2), 129-138.

Terzaghi, E., Wild, E., Zacchello, G., Cerabolini, B.E.L., Jones, K.C., Di Guardo, A., 2013. Forest filter effect: role of leaves in capturing/releasing air particulate matter and its associated PAHs. Atmos. Environ. 74 (8), 378-384.

Vos, P.E.J., Maiheu, B., Vankerkom, J., Janssen, S., 2013. Improving local air quality in cities: to tree or not to tree? Environ. Pollut. 183 (12), 113-122.

Wang, L., Liu, L.Y., Gao, S.Y., Hasi, E., Wang, Z., 2006. Physicochemical characteristics of ambient particles settling upon leaf surfaces of urban plants in Beijing. J. Environ. Sci. 18 (5), 921-926.

Weber, F., Kowarik, I., Saumel, I., 2014. Herbaceous plants as filters: immobilization of particulates along urban street corridors. Environ. Pollut. 186 (3), 234-240.

Yan, J., Lin, L., Zhou, W., Ma, K., Pickett, S.T.A., 2016. A novel approach for quantifying particulate matter distribution on leaf surface by combining SEM and object-based image analysis. Remote Sens. Environ. 173 (1), 156-161.

Zhou, W., Troy, A., 2008. An object-oriented approach for analysing and characterizing urban landscape at the parcel level. Int. J. Remote Sens. 29 (11), 3119-3135. 